\title{
实 \\ Las mujeres en la publicidad: análisis, legislación y aportaciones para un cambio
}

\author{
Raquel Santiso Sanz \\ DEPARTAMENTO DE PSICOLOGÍA Y SOCIOLOGÍA \\ UNIVERSIDAD DE ZARAGOZA
}

La publicidad se ha convertido para las mujeres en un espejo distorsionado de la realidad, un espejo que sólo muestra a mujeres bellas, jóvenes y delgadas, con las fuertes repercusiones que esto puede suponer para la salud entendida en su sentido más amplio, así como para el autoconcepto y para la configuración a nivel social de los imaginarios colectivos, los papeles sociales y los estereotipos acerca de cómo debe ser una mujer y lo que se espera de ella. El objetivo de este artículo es analizar la evolución de imágenes de mujer que están ofreciendo los anuncios publicitarios, conocer qué recoge la legislación de publicidad al respecto, explicar qué medidas se han tomado ya en la línea de intentar evitar las desigualdades y tratar de completar y profundizar en el análisis crítico sobre este tema con visiones y aportaciones propias y de otras personas expertas en la materia.

Palabras clave: publicidad, mujer, medios de comunicación, belleza, delgadez, juventud, legislación, observatorio de publicidad. 


\section{Las mujeres en la publicidad: análisis, legislación}

y aportaciones Raquel Santiso Sanz

\section{para un cambio}

«La publicidad se ha convertido para nosotras en un espejo distorsionado de un mundo poblado de mujeres delgadísimas, jóvenes y radiantes(...) mujeres que nos venden como perfectas, modelos ideales que nos recuerdan cada día "cómo tenemos que ser».La publicidad, como el espejo de la madrastra del cuento, nos refleja a las «más hermosas», y se olvida que ese mundo al que pertenecen es tan lejano e irreal como el país de las hadas. Así mujeres fuertes, sanas y guapas torturan su cuerpo sometiéndolo a regímenes desquiciados, sesiones brutales de gimnasio, tratamientos estéticos absurdos...y sus cuerpos nunca se acercan a la imagen que quieren que el espejo les refleje.»

Eva Rodríguez y Lita Gómez (Los cuentos del espejo mágico. Mujeres y salud)

\section{Análisis de la situación de las mujeres en la publicidad}

Es algo evidente que no aparece cualquier modelo de mujer en los medios de comunicación de masas y más concretamente en la publicidad. Las mujeres no estamos en ellos bien representadas y por ello no son un espejo que nos permita mirarnos o que muestre la realidad. Aparecen muy pocas mujeres mayores, gordas, feas, «normales», con poder... ¿Es que estas mujeres no existen o no se merecen aparecer en los medios o en los anuncios? ¿Por qué es necesario esconderlas y dar una imagen equivocada de la mujer en la sociedad española? ¿Por qué sí que aparecen hombres mayores, descuidados, con canas, calvos, barrigones, feos y no pasa nada? 
Los medios de comunicación de masas son, junto con la familia y la escuela, uno de los agentes fundamentales de socialización de nuestra época.

«La publicidad juega un papel decisivo como instrumento de comunicación social, siendo capaz (...) de conformar modelos colectivos de valores y comportamientos, ofreciendo al público, no sólo productos, sino también modelos de actitudes, formas de vida e imágenes paradigmáticas que orientan $\mathrm{y}$, en muchos casos, definen las necesidades y los deseos de las personas.» (Peña y Frabetti, 1990: 5)

La publicidad no sólo parte de la realidad, sino que también la crea. Para empezar ha de crearnos como consumidores. Para ello nos observa, estudia nuestras vidas y nuestros más íntimos deseos y sueños. Pero no para reproducirlos, sino para hacernos salir de ellos, desear ser otras personas, parecernos a otros, vivir otras vidas... Y para hacer que sus diferentes receptores sueñen al unísono, un sueño siempre transformable en consumo, ha de partir de lo que ya compartíamos. De aquí su lado conservador, su tendencia a repetir lo más sólidamente asentado. Como indica Victoria Camps (1998), la publicidad homogeneiza al consumidor, lo convierte en un prototipo, a la vez que se alimenta de estereotipos. Y para llegar al mayor número de personas ha de utilizar las imágenes más mayoritarias, que son las más retrógradas y resistentes al cambio.

Los estudios realizados en torno a esta cuestión, siguiendo las aportaciones de Peña y Frabetti (1990), revelan que la publicidad todavía recoge una visión sexista de las mujeres y de los papeles que se les han asignado tradicionalmente. Así, frecuentemente prevalece la consideración de la mujer como un objeto sobre la de persona, utilizando su cuerpo como reclamo, a la vez que se reitera su papel dependiente del hombre y se le asigna en exclusiva los papeles relacionados con la vida doméstica y el cuidado de las personas.

«La persistencia de estereotipos sexistas se debe en gran parte a la proyección a través de los medios de comunicación de imágenes negativas y degradantes de la figura de las mujeres, en las que se aprecia una clara separación entre los papeles de hombres y mujeres como trabajadores o cuidadoras, activos o a cargo, productivos o no reproductivas, que dificulta la participación paritaria de mujeres y hombres en la vida familiar y social.» (III Plan para la igualdad de oportunidades entre mujeres y hombres. 1.997-2.000:59) 
La publicidad no es entonces un espejo real de los modos de vivir, pensar y actuar, porque incorpora todo desde su propia lógica. Recurre a los símbolos asentados y de eficacia segura, pero buscando fallas en la perfección de las vidas, los comportamientos excepcionales y extraños, o incluso los rechazados, pero secretamente deseados, o que llegarán a serlo con la ayuda de la publicidad. El principal mensaje de la publicidad viene a ser que consumir es el remedio mágico contra las frustraciones. Pero no podemos olvidar que la actuación publicitaria no es inocente porque permanece siempre un fin detrás: vendernos algo y compra más quien más baja tiene la autoestima. Y si a este hecho le sumamos que todavía hoy son principalmente las mujeres quienes más compran, la manipulación está servida.

María Elósegui Itxaso (1998) en Los roles de la mujer y el varón en la sociedad española y su reflejo en los anuncios de te levisión ${ }^{1}$, hace un estudio sobre el papel asignado a las mujeres en los anuncios de televisión desde los años 60 hasta la actualidad, diferenciando tres etapas aquí resumidas:

- En la primera, desde los años 60, la mujer aparece subordinada al varón. Es una etapa en la que las mujeres son consideradas diferentes y así lo apoya la normativa jurídica en la que queda patente la desigualdad. La mujer siempre aparece en estos anuncios realizando tareas de la casa, atareada, cuidando de los hijos y dependiente económicamente del marido. Sólo ciertos trabajos se consideran relacionados con la mujer, tres en concreto, la educación, la enfermería y el secretariado. Esta fue la visión mayoritaria de la sociedad española hasta aproximadamente 1975.

- En la segunda etapa y a raíz de las reivindicaciones feministas de los años 70, las mujeres ya son iguales ante la ley. Pero en los anuncios las reivindicaciones feministas apenas tuvieron reflejo. Quizás por la inicial resistencia al cambio en la sociedad y el miedo de los hombres a perder su predominio en la vida pública. Tampoco hay que olvidar

1 El estudio viene acompañado de un interesante vídeo que recoge anuncios de las tres etapas diferenciadas y su análisis. 
que la publicidad estaba en manos de los hombres (hecho que todavía hoy no ha cambiado demasiado). La liberalización de la mujer se refleja en los anuncios en la forma de vestir de las mujeres, con pantalones y su relación con el tabaco y la bebida, antes consideradas como algo masculino. La legislación, al negar las diferencias entre mujeres y hombres, tampoco hace distinciones y se retiran las leyes proteccionistas hacia la mujer, incluso la relacionada con el embarazo y la lactancia. La mujer ve muy difícil hacer compatible las exigencias laborales hechas a medida de los hombres con la crianza de los hijos, convirtiéndose en una superwoman y asumiendo la «doble jornada laboral», trabajando dentro y fuera del hogar.

- En la tercera etapa de anuncios se reivindica la corresponsabilidad o el compartir roles de hombre y de mujer, tanto en el mercado de trabajo como en el ámbito doméstico. Por primera vez comienzan a aparecer anuncios en los que el padre aparece ocupándose de la casa, cuidando de los hijos, etc. Las mujeres aparecen, por su parte, con maletín y en trabajos de responsabilidad, no sólo en los típicos trabajos de mujer. Y la legislación avanza también en este mismo sentido de la corresponsabilidad. Pero en esta etapa aparece una nueva forma de tratar a la mujer como un objeto más de consumo, muy potenciada desde la publicidad. En los anuncios de etapas anteriores no aparecía este matiz de utilización de la figura de la mujer con fines consumistas y hedonistas, ni como objeto de placer, al servicio y subordinada al instinto del hombre. Este es el principal estereotipo discriminatorio que nos encontramos hoy contra la mujer. La mujer es tratada como un objeto de consumo sexual. En muchos anuncios la mujer aparece como guapa y sexy. Lo que vale es su cuerpo, pero no su capacidad intelectual, sus talentos, su personalidad, etc.

«Es un nuevo tipo de subordinación y de dependencia de la mujer con respecto al varón.Es en realidad un retroceso al modelo uno, con nuevas connotaciones.» (Elósegui, 1998: 17)

Es de este tercer modelo de la mujer en la publicidad actual como un objeto sexual de donde quiere partir mi análisis profundizando en algunas cuestiones acerca de la imagen de la 
mujer y de los valores femeninos que se imponen en el físico de la mujeres: la belleza, la juventud y la delgadez.

\section{Belleza, juventud y delgadez}

Los valores máximos que la publicidad actual asocia con un cuerpo femenino son, la belleza, la juventud y la delgadez. Hay toda una serie de mentiras en torno a estos valores, que a base de repetírnoslas desde los medios de comunicación se han ido convirtiendo en verdades absolutas e incuestionables. Por ejemplo, que la belleza, juventud y delgadez son condiciones indispensables para el acceso al poder y al éxito y que cualquier mujer puede conseguirlo con esfuerzo.

Como sugiere Naomi Wolf (1991), ${ }^{2}$ la belleza, delgadez y juventud femenina ya no son unos dones del cielo que caían como una bendición sobre algunas elegidas. Ahora se han transformado en un culto universal, en obligación cotidiana y obsesiva y en ineludibles imperativos sociales, sin los cuales las mujeres, sienten su identidad devaluada y la amenazante sombra del fracaso personal, muchas veces con trágicas consecuencias. La mujer hoy se siente obligada a vivir en la perfección.

El físico de las mujeres que aparecen en los medios de comunicación en general y en la publicidad en particular, es cada vez más irreal lo cual implica riesgos para la salud de las mujeres al buscar un ideal corporal inalcanzable, para su autoestima y además supone una importante dedicación temporal al cuidado del cuerpo y la búsqueda de la belleza. Se sigue privilegiando, como en otras épocas, el físico frente a la intelectualidad o a otras potencialidades y logros personales en la vida de las mujeres. El cuidado del físico es una nueva obligación más para las mujeres que la autora Naomi Wolf (1991) ha llamado «el tercer turno laboral».

Sólo un modelo corporal muy estricto es capaz de representar en la publicidad a la belleza femenina. Para las mujeres lo que hace a los hombres atractivos no es la conformidad de su fí-

2 Para una mayor profundización en estos aspectos véase WOLF, Naomi (1991) El mito de la Belleza, Emecé, Barcelona. Es un libro que no tiene desperdicio, agotado, por cierto. 
sico con los modelos de belleza imperantes. Ello ha permitido una gran variedad de modelos de belleza masculina y también que la propia belleza no sea determinante de la vida sentimental de los hombres, como sigue siendo la vida sentimental, y también la social y la profesional de las mujeres.

Como escribe Rita Freedman:

«En la actualidad nos mide (y a menudo nos rechaza) una cultura que reduce la escala de la belleza femenina a un tamaño más pequeño que nunca.» (Freedman, 1991: 112)

De acuerdo con lo que apunta Gordon (1994), hace una generación las modelos pesaban, por término medio, un $8 \%$ menos que las mujeres normales, mientras hoy pesan un $23 \%$ menos. Es por todos sabido que muchas modelos, bailarinas, actrices y otras mujeres de éxito son anoréxicas. En esta loca paradoja resulta que quienes ahora anuncian cremas anti-celulitis o anti-edad son jóvenes esbeltas que no tienen todavía ni celulitis ni arrugas. Pero, a pesar del engaño evidente, el mensaje de belleza que se nos manda desde la publicidad es sutil:

«Inténtelo, se lo debe a usted misma, si no la culpa será exclusivamente suya.De este modo aparece la culpa sumada al estigma de verse fea, gorda o canosa.» (Freedman, 1991: 258)

La obligación y presión social hacia las mujeres para conservar un cuerpo delgado al precio que sea y ser así mejor aceptadas socialmente y poder acceder al éxito, está suponiendo una negación de la propia naturaleza del cuerpo humano. Tomar menos calorías de las necesarias se traduce en una disminución de la resistencia intelectual y emocional. Estar a dieta constantemente crea un tipo de personalidad cuyos rasgos distintivos son la pasividad, la ansiedad y la emotividad. Adelgazar más allá de un límite natural supone también renunciar a la sexualidad. Lo que ocurre en el cuerpo de las mujeres repercute en su mente. Hacer régimen puede convertirse, de este modo, en una verdadera enfermedad social, que llega a sus extremos en la anorexia y en la bulimia nerviosas. Pero la norma general para las adolescentes y mujeres es tener conflictos respecto a la alimentación y miedo a engordar en nuestra cultura, a la vez que las imágenes de delgadez que nos ofrecen los medios de comunicación se han vuelto cada vez más rigurosas e irreales. 
Naomi Wolf (1991) afirma que son las características de personalidad de quien hace dieta y no la delgadez en sí misma lo que se desea crear. Es decir, lo que se busca en realidad es una conducta, no una apariencia. Ponerse a dieta es uno de los más potentes sedantes políticos en la historia de la mujer. Una población así es fuertemente maleable porque la preocupación por el peso crea un total derrumbamiento de la autoestima y de la eficacia. Odiar la forma del propio cuerpo es una forma de odiar la femineidad. El hambre hace que las mujeres se sientan mal y piensen mal y hace que las mujeres con éxito se sientan fracasadas. Virginia Wolf decía:

«No se puede pensar bien, amar bien, dormir bien, si no se ha cenado bien.»

La edad vuelve invisibles a las mujeres en la publicidad porque las mujeres a partir de determinada edad, sobre todo si aparentan la edad que tienen, ya no aparecen. El hecho de que los rostros femeninos maduros no sean habituales en los medios de comunicación y especialmente en la publicidad, transmite un mensaje social que deja huella en la imagen corporal y en los cuidados que hacia el cuerpo se tendrán. Las ausencias hablan muchas veces más que las presencias.

«Mentir acerca de la edad es parte de la mística femenina que aprendemos muy temprano en la vida. Maquillamos nuestra edad igual que nuestro rostro, para parecer lo que no somos.(...) No preguntar la edad de una mujer y no decirla después de cierto punto se ha convertido en una broma universal.» (Freedman,1991: 232)

Envejecer no se considera bello en la actualidad en parte porque con el tiempo las mujeres adquieren mayor poder y porque los lazos entre las generaciones de mujeres pueden resultar peligrosos. Así las mujeres maduras temen a las jóvenes y las jóvenes a las maduras en cuanto a físico se refiere. Al no poder identificarse unas generaciones de mujeres con otras, seguimos siendo vulnerables a la aprobación externa. Nos encontramos con que, de nuevo, hoy el cuerpo de las mujeres es principalmente evaluado desde fuera, desde la mirada del otro.

La presión y obligación social hacia las mujeres de mantenerse jóvenes para ser más aceptadas supone negar su propia trayectoria. Borrar la edad del rostro es borrar la identidad, el poder y la historia. No poder identificarse con mujeres mayores 
es una manera de negar o no poder imaginar el futuro y no poder sentir orgullo por la propia vida.

«Las implicaciones comerciales del culto a la juventud son obvias. Cuanto mayor sea su angustia por verse mayor, más deseos tendrá de comprar productos que la hagan lucir más joven. Pero las implicaciones políticas y sociales en el culto a la juventud son más sutiles. Si usted está envuelta en una imagen adolescente, es muy probable que no se le tome en serio, y además, se le niega la visión de su propia madurez.(...) A causa del culto a la juventud las mujeres no logran abrazar la posibilidad de sentirse poderosas en la segunda mitad de sus vidas.» (Freedman, 1991:218)

No se puede quitar importancia al papel que los medios de comunicación y los intereses comerciales tienen en la difusión de estos ideales de belleza, delgadez y juventud para la mujer. El bombardeo de imágenes y mensajes al que nos someten hacen que se acepten como normales ciertas distorsiones de las proporciones reales del cuerpo y las consecuencias que pueden tener para la salud. La publicidad es contradictoria pero se asimila y acepta como normal y válida y es poco, o nada, sometida a crítica. La mujer hoy supone uno de los mayores consumidores de los productos con mayor mercado (dietéticos, cosméticos, estéticos y la moda) y todos ellos giran en torno a estos valores femeninos de belleza, delgadez y juventud.Interesa que las mujeres tengan la autoestima baja porque una persona con la autoestima baja compra más y para conseguir eso nada mejor que el ataque psicológico para debilitar a la mujer, que sigue siendo la principal compradora en nuestra sociedad.

Es habitual encontrar en revistas, anuncios y catálogos de moda mujeres con expresiones poco felices, pálidas, excesivamente delgadas, con características relacionadas con la enfermedad o la locura, con estética de mujeres maltratadas, imágenes casi pornográficas de niñas y adolescentes... Todo ello acompañado de mensajes contradictorios, engañosos y manipuladores. Tampoco se nos advierte, por ejemplo, que las revistas dirigidas a mujeres están promocionadas y financiadas por los productos que anuncian y que éstos no sólo están presentes en los anuncios sino que además condicionan el contenido de los artículos de la revista, manipulando también desde aquí los mensajes que se dirigen a las mujeres con el fin de seguir potenciando el consumo. 
Las consecuencias de toda esta manipulación son claras: El cuerpo de la mujer se ha convertido en su peor enemigo, en lugar de sacrificio, frustraciones, culpas, penitencias y renuncias. El cuerpo ya no se concibe como un todo que es, sino como un conjunto de pedazos que gustan más o menos.

"Las mujeres tendemos a vivenciar nuestro cuerpo más en términos de cómo luce que de cómo nos sentimos. El cuerpo se convierte, en especial para las mujeres, en un elemento de exhibición en lugar de ser un instrumento de placer sensual.» (Freedman, 1991: 176)

La búsqueda de belleza, juventud y la delgadez al precio que sea, además hace primar la competencia frente a la solidaridad, aparte de los sentimientos de vulnerabilidad, inseguridad y baja autoestima que provoca.Lo que está en juego es la salud de las mujeres pero entendida en su sentido más amplio.

Con todo este análisis no quiero ni pretendo negar la fuente de creatividad y placer que el cuidado de un cuerpo supone, ni lo importante que es estar a gusto con el propio cuerpo, ni satanizar el uso de cosméticos u otros productos. Simplemente se ha tratado de hacer consciente el gran poder de la publicidad para llevarnos a su terreno y conseguir sus fines, remodelando los imaginarios e ideales sociales.

Aprender a construir modelos de mujeres alternativos a los que nos ofrece la sociedad de consumo y más acordes con los de la vida cotidiana es un reto que tenemos por delante. Porque como dice Rita Freedman «tenemos el derecho y la responsabilidad de compararnos con modelos reales. El derecho de sentirnos cómodas dentro de nuestra propia piel.» (Freedman, 1991: 287) Es vital, para ello, entender que no es necesario cambiar nuestros cuerpos sino las reglas de este absurdo juego.

\section{Legislación de publicidad}

Veamos ahora qué recoge la legislación relacionada con publicidad, mujer y salud al respecto. Algunos ejemplos:

La Ley 34/1988, de 11 de noviembre, General de Publicidad, en su artículo $3^{\circ}$ define como publicidad ilícita «la que atente contra la dignidad de la persona y derechos reconocidos en la 
Constitución especialmente en lo que se refiere a la infancia, la juventud y la mujer». En su artículo 8, permite regular la publicidad de los productos, bienes, actividades y servicios susceptibles de generar riesgos para la salud o seguridad de las personas y concretamente «la forma y condiciones de difusión de los mensajes publicitarios»

La Ley 25/1994, de 12 de julio, sobre Ejercicio de las Actividades de Radiodifusión Televisiva, declara «ilícita, en todo caso, la publicidad por televisión que fomente comportamientos perjudiciales para la salud o la seguridad de las personas» (Artículo 9.1)

La Ley 14/1986, de 25 de abril, General de Sanidad, ordena que las Administraciones públicas, en el ámbito de sus competencias, realicen «un control de la publicidad y propaganda comerciales para que se ajusten a criterios de veracidad en lo que atañe a la salud y para limitar todo aquello que puede constituir un perjuicio para la misma» (Artículo 27). Así mismo prevé la inspección y control de la promoción y publicidad de los centros y establecimientos sanitarios (Artículo 30.1) y encomienda «a la Administración sanitaria del Estado valorar la seguridad, eficacia y eficiencia de las tecnologías relevantes para la salud y la asistencia sanitaria» (Artículo 110).

El artículo 8 de la Ley 4/1980, de 10 de enero, de Estatuto de la Radio y Televisión, en su apartado 1. j) atribuye inequívocamente al Consejo de Administración del Ente público el «dictar normas reguladoras respecto a la emisión de publicidad por RTVE, atendidos el control de calidad de la misma, el contenido de los mensajes publicitarios y la adecuación del tiempo de publicidad a la programación y a las necesidades de los medios».

En la resolución de 17 de abril de 1990, de la dirección general de medios de comunicación social, por la que se hacen publicas las normas de admisión de publicidad, aprobadas por el consejo de administración del ente publico radio-televisión española, queda claro en su artículo 3 que «Los anunciantes deberán desvelar inequívocamente el carácter publicitario de sus anuncios. No incurrirán en ninguno de los supuestos de publicidad ilícita previstos en el título II de la Ley General de Publicidad;y respetarán especialmente el derecho al honor, a la intimidad personal y familiar y a la propia imagen.» 
En la ley 25/1994, de 12 de julio, por la que se incorpora al ordenamiento jurídico español la directiva 89/552/CEE, sobre la coordinación de disposiciones legales, reglamentarias y administrativas de los estados miembros relativas al ejercicio de actividades de radiodifusión televisiva se considera publicidad ilícita «además de lo que resulta de lo dispuesto en el artículo 3 de la Ley 34/1988, de 11 de noviembre, General de Publicidad, es ilícita, en todo caso, la publicidad por televisión que fomente comportamientos perjudiciales para la salud o la seguridad de las personas o para la protección del medio ambiente; atente al debido respeto a la dignidad humana o a las convicciones religiosas y políticas; o discrimine por motivos de nacimiento, raza, sexo, religión, nacionalidad, opinión, o cualquier otra circunstancia personal o social.Igualmente, será ilícita la publicidad que incite a la violencia o a comportamientos antisociales, que apele al miedo o a la superstición o que pueda fomentar abusos, imprudencias, negligencias o conductas agresivas. Tendrá la misma consideración la publicidad que incite a la crueldad o al maltrato a personas o animales o a la destrucción de bienes culturales o naturales. (Artículo 9)

Conforme al artículo 18.1 de la Constitución, los Derechos al Honor, a la Intimidad Personal y Familiar y a la Propia Imagen tienen el rango de fundamentales, y hasta tal punto aparecen realzados en el texto constitucional que el artículo 20.4, dispone que el respeto de tales derechos constituya un límite al ejercicio de las Libertades de Expresión que el propio precepto reconoce y protege con el mismo carácter de fundamentales.

La ley orgánica 1/1982 de 5 de mayo de protección civil del derecho al honor, a la intimidad personal y familiar y a la propia imagen en su artículo Primero dispone que «el Derecho Fundamental al Honor, a la Intimidad Personal y Familiar y a la Propia Imagen, garantizado en el artículo 18 de la Constitución, será protegido civilmente frente a todo género de intromisiones ilegítimas, de acuerdo con lo establecido en la presente Ley Orgánica. El Derecho al Honor, a la Intimidad Personal y Familiar y a la Propia Imagen es irrenunciable, inalienable e imprescriptible.»

Como puede comprobarse en estos ejemplos, legislación que trate favorablemente a la mujer no falta en torno a este tema, otra cosa es que se cumpla. El caso es que, pese a la abundancia de leyes, la publicidad no mejora. 
Victoria Camps (1998) apunta dos razones por las que la legislación es insuficiente: La primera es debida a la ambigüedad de la propia ley. Es realmente difícil y complejo poder indicar criterios objetivables respecto a formas de vida retrógradas 0 sobre si perjudica o no a la imagen de la persona.

"Conceptos como dignidad, autoestima, intimidad, no es que sean conceptos vacíos, pero son conceptos cuyo contenido lo van dando, precisamente, las ideas que marcan avances sociales, la jurisprudencia que va concretando la aplicación de los principios legales.» (Camps, 1998: 124)

La segunda razón que apunta la autora es que la ley sirve de poco, si no existe, al mismo tiempo, voluntad de autocontrol.

"La defensa de la dignidad de la mujer es algo relativamente reciente. Las mentalidades y los mensajes sociales son subsidiarios todavía -incluso en mujeres feministas y avanzadas- de estereotipos que impiden tomar conciencia de la degradación de ciertas imágenes de la mujer.» (Camps, 1998: 126)

\section{El observatorio de publicidad}

El Observatorio de la Publicidad fue creado por el Instituto de la Mujer del Ministerio de Trabajo y Asuntos Sociales en 1994 para recoger denuncias sexistas y promover la rectificación o retirada de los mensajes más criticados y discriminatorios de acuerdo con la Ley 34/88 General de Publicidad que en su artículo $3^{\circ}$ define como publicidad ilícita «la que atente contra la dignidad de la persona y derechos reconocidos en la Constitución especialmente en lo que se refiere a la infancia, la juventud y la mujer» y el artículo 5 del III Plan de Igualdad de Oportunidades para las mujeres (1997-2000) que establece «la necesidad de fomentar una imagen equilibrada y no estereotipada de las mujeres en los medios».

El Observatorio de la Publicidad se constituye así como un foro de observación, análisis y canalización de denuncias a nivel nacional. Consta de dos instrumentos: una línea 900 durante las 24 horas además de una dirección de correo electrónico y del Consejo Asesor de Imagen (16 profesionales de distintos colectivos que colaboran con el Instituto de la Mujer). 
En el año 2000 el Observatorio de la Publicidad del Instituto de la Mujer recibió 339 denuncias por publicidad sexista. Los estereotipos más repetidos son:

- La reducción de la mujer a la función reproductiva y atribución exclusiva del cuidado de la familia y el hogar.

- La presentación de las mujeres como objeto sexual pasivo (mas del $50 \%$ ). Se refieren al uso del cuerpo femenino para la venta de productos sin relación con él, a modo de reclamo publicitario.

- Situarla como una propiedad/carga del varón.

El observatorio de la publicidad aparece como un instrumento indispensable para combatir la publicidad sexista, y más allá de eso, aquella que como hemos visto atenta contra la salud de las mujeres. Pero se hace necesaria una difusión mayor del observatorio, es decir, una mayor concienciación social de que existe y una mayor presencia y publicidad de sus actuaciones y efectos. Por otra parte, la retirada de anuncios sexistas no es suficiente porque todos los anuncios publicitarios ya tienen de por sí una vida corta, pero sabemos que esto ya es suficiente para que causen efecto. Además, es imposible retirar los anuncios publicitarios de revistas por lo que la influencia sigue teniendo su efecto sobre las mujeres.

A estas razones habría que sumar la falta de conciencia generalizada y sobre todo, el fuerte control que ejerce el poder económico sobre el resto de los órdenes sociales.

\section{Tratando de concluir}

De todo lo dicho anteriormente se desprende que no existe una correlación real entre el papel que las mujeres están jugando en estos momentos en nuestra sociedad y la imagen que aparece de ellas en la publicidad. Nos hemos acostumbrado tanto a lo que nos muestra que la manipulación a la que nos somete es cada vez más evidente y directa e implica riesgos para nuestra salud física y psicológica.

No se puede negar el importante poder de la publicidad para perpetuar modelos, crear nuevos o ayudar a romperlos. Sería 
por ello importante tratar de utilizarla a favor de las personas y promover desde las plataformas sociales, los niveles políticos, administrativos e institucionales un trato humano y no abusivo de la misma.

«Debemos aprender a aprovechar las ventajas de la publicidad para vender lo que vale la pena vender. Vender cultura o vender valores. ¿Por qué tantos remilgos y miedo a las ideologías y tanta transigencia, en cambio, frente a las mil majaderías que los productos nos obligan a comprar?» (Camps, 1998: 128)

Se han dictado normas muy estrictas para publicitar tabaco o bebidas alcohólicas e incluso el Gobierno adoptó medidas de tipo fiscal, mediante la implantación de impuestos especiales, limitando e incluso prohibiendo la publicidad asociada.En cambio con el tratamiento que se está haciendo de la imagen de las mujeres en los medios de comunicación y en la publicidad no se está haciendo a efectos reales mucho, puesto que, de acuerdo con los datos del año 2000 del Observatorio de la Publicidad del Instituto de la Mujer, el estereotipo de la mujer como objeto sexual y la imagen de la mujer como bella, joven y delgada no sólo persiste sino que ha aumentado respecto a años anteriores. Las acciones que a nivel individual se puedan tomar son insuficientes por sí solas para generar un cambio. Para lograrlo es imprescindible la unión de las fuerzas sociales con los poderes públicos.

\section{Referencias bibliográficas}

CAMPS, V. (1998). El siglo de las mujeres. Cátedra.

ELÓSEGUI ITXASO, M. (1998). Los roles de la mujer y el varón en la sociedad española y su reflejo en los anuncios de tele visión. (Vídeo y guía didáctica). Instituto Aragonés de la mujer en colaboración con el ICE y la Facultad de Derecho de la Universidad de Zaragoza.

FREEDMAN, R. (1991). Amar nuestro cuerpo. Guía práctica para mujeres. Cómo gustarnos a nosotras misma. Barcelona: Edic. Paidós Ibérica.

GORDON, R. A., (1994). Anorexia y bulimia. Anatomía de una epidemia social. Barcelona: Editorial Ariel. 
PEÑA-MARÍN, C. y FRABETTI, C.(1990). La mujer en la publici dad. Madrid: Instituto de la Mujer. (Con Vídeo).

RODRíGUEZ, E. y GÓMEZ, L. (2000). «Los cuentos del espejo mágico. Mujeres y salud», Meridiana. Revista del Instituto Andaluz de la Mujer, no 16 . Sevilla: Junta de Andalucía, pp. 48-50, primer trimestre de 2000.

SANCHEZ LEYVA, Mํㅡㄴ J. (1999). La presentación de las mujeres en los medios de comunicación. En: NUÑO GÓMEZ, L., Mujeres: de lo privado a lo público. Madrid: Tecnos.

VENTURA, L. (2000). La tiranía de la belleza. Las mujeres ante los modelos estéticos. Barcelona: Plaza y Janés.

WOLF, N. (1991). El mito de la belleza. Barcelona: Emecé editores.

III Plan para la igualdad de oportunidades entre mujeres y hom bres. 1.997-2.000.

Il Plan de Acción Positiva para las mujeres en Aragón. 1.9972.000.

Ley 34/1988, 11 de noviembre, General de Publicidad. B.O.E. núm. 274, de 15 de noviembre de 1988.

Ley 4/1980, de 10 de enero, de Estatuto de la Radio y la Televisión.

Resolución de 17 de abril de 1990, de la dirección general de medios de comunicación social, por la que se hacen públicas las normas de admisión de publicidad, aprobadas por el con sejo de administración del ente público radio-televisión espa ñola. BOE nำ 95, de 20 de abril de 1990.

Ley 22/1999, de 7 de junio, de modificación de la ley 25/1994, de 12 de julio, por la que se incorpora al ordenamiento jurí dico español la directiva 89/552/CEE, sobre la coordinación de disposiciones legales, reglamentarias y administrativas de los estados miembros, relativas al ejercicio de actividades de radiodifusión televisiva. BOE nำ136, de 8 de junio de 1999

Real decreto 1462/1999, de 17 de septiembre, por el que se aprueba el reglamento que regula el derecho de los usuarios del servicio de televisión a ser informados de la programa ción a emitir, y se desarrollan otros artículos de la ley 25/1994, de 12 de julio, modificada por la ley 22/1999, de 7 de junio. BOE no 233, de 29 de septiembre de 1999.

Real decreto 1599/1997, de 17 de octubre, sobre productos cos méticos. BOE no 261, de 31 de octubre de 1997. 
Real decreto 1907/1996, de 2 de agosto, sobre publicidad y pro moción comercial de productos, actividades o servicios con pretendida finalidad sanitaria. BOE ํㅜ 189, de 6 de agosto de 1996.

Ley orgánica 1/1982 de 5 de mayo de protección civil del dere cho al honor, a la intimidad personal y familiar y a la propia imagen.

Código de Conducta Publicidad (AAP) de la Asociación de Autocontrol de la Publicidad, aprobado en su Asamblea General Ordinaria celebrada el 14 de abril de 1999.

Código Ético sobre Publicidad en Internet de la Asociación de Autocontrol de la Publicidad, aprobado en su Asamblea General Ordinaria celebrada el 14 de abril de 1999. 